\title{
Poemas em busca de poetas: Uma reflexão sobre a multiplicidade do inconsciente
}

\author{
Poems in search of poets: A reflection on the multiplicity of the unconscious
}

Jussara Maria Weigert Janowski

Psicóloga, doutora em Psicologia pela Universidade de Brasília (UnB), professora titular da Pontifícia Universidade Católica do Paraná (PUCPR), Curitiba, PR Brasil, e-mail:

jussara.janowski@pucpr.br

Recebido: $19 / 11 / 2012$ Received: 11/19/2012

Aprovado: 22/03/2013 Approved: 03/22/2013

\begin{abstract}
Resumo
A ideia da pluralidade em psicanálise é tipicamente junguiana. Jung, a partir da teoria dos complexos, desenvolveu seu trabalho dando prioridade ao inconsciente. É o fundo comum da humanidade quem traz novas criações e possibilidades; e nós, junto com desenvolvimento pessoal, fazemos parte de uma base comum da humanidade: o inconsciente coletivo. Foi com esse conceito que Jung trouxe uma nova perspectiva de abordar a psique. Fenando Pessoa poeta recebe personagens, poemas e imagens do inconsciente, consegue acolhê-las e trabalhar com as imagens primordiais que lhes chega. Em suas obras, ao mesmo tempo em que o autor joga com o real e a fantasia, nos revela o surgimento desse sujeito múltiplo. A invenção dos heterônimos pelos quais assume identidades diferentes foi a resposta encontrada por Pessoa para a identidade cultural representada pelo sujeito unificado, em crise. Originados no espaço da invenção, os heterônimos explodem de maneira profética anunciando a fragmentação do indivíduo moderno. Ao nascer do fundo comum, Campos, Reis e Caeiro - manifestações sinceras - ganham vida própria e os diferentes "eus" são tratados como elementos autônomos. 0 poeta observa de longe, questiona sua unidade e se põe em processo. É um trabalho sem fim a tarefa das subpersonalidades em busca da unidade, da totalidade, tema que se faz presente em toda a sua obra. Jung assim como Pessoa concebe a psique como pluralidade e desconstrói a ideia de sujeito unitário. A partir dessa percepção se rompe o conceito de unidade da psique e a preponderância da vontade.
\end{abstract}

Palavras-chave: Subpersonalidades. Complexos. Heterônimos. Psicologia analítica.

\section{Abstract}

The idea of plurality in psychoanalysis is typically Jungian. Jung through complex theory developed his work giving priority, unconscious world. It is the common background of humanity that brings new creations and possibilities, and we are together with a personal development of a common humanity basis: the collective unconscious. It was with this concept that Jung has brought a new perspective to broach the psyche. Fernando Pessoa, poet receives characters, poems and images of the unconscious, welcome them and work with the primordial images that arrive. In his works, while the author plays with real and fantasy, reveals us the emergence of 
this multiple subject. The invention of the heteronymous, in which assumes different identities was the answer found by Pessoa for cultural identity represented by unified subject, in crisis. Originated in the space of the invention, the heteronymous explode in a prophetic manner announcing the fragmentation of the modern individual. At birth of the common fund, Campos, Reis and Caeiro - "sincere manifestations" — come to life and the different "selves" are treated as autonomous elements. The poet observes from a distance, questions his unity and puts himself in process. It is an endless work the task of sub personality in search of unity, of wholeness, topic that is present in all his work. Jung as well as Pessoa, conceives the psyche as plurality and deconstructs the idea of an only subject. This perception breaks off the concept of psyche unity and the preponderance of the will.

Keywords: Sub-personalities. Complexes. Heteronymous. Analytical psychology.

\section{Introduç̃̃o}

"Somos um fluxo de personificações Qual é a parte desconhecida de mim mesmo que me guia?" Fernando Pessoa

A ideia da pluralidade em psicanálise é tipicamente junguiana. A partir da teoria dos complexos, Jung desenvolveu seu trabalho dando prioridade ao fundo comum ao mundo interno, ao inconsciente. É o fundo comum da humanidade quem traz as novas criações e possibilidades; e nós, junto com o desenvolvimento pessoal, fazemos parte de uma base comum da humanidade: o inconsciente coletivo. Foi com o conceito de inconsciente coletivo que Jung trouxe uma nova perspectiva de abordar a psique.

Como Jung traça a ideia da pluralidade da psique? É através da teoria dos complexos que ele trabalha com a ideia do fundo comum, ou seja, as imagens primordiais. Os complexos podem ser pensados como subpersonalidades, como personalidades fragmentadas; possuem um tipo de consciência independente, como se possuíssem um eu próprio, cada um operando a sua maneira e com identidade própria, mostrando às vezes sua superioridade com relação à vontade consciente.

Todos nós temos uma psique múltipla porque temos complexos tanto de cunho pessoal como provenientes do inconsciente coletivo. De acordo com essa teoria, o complexo do eu, centro da consciência humana, é um entre os vários complexos existentes. Os outros complexos podem aparecer ou não associados ao complexo do eu: podem tornar-se conscientes ou não; nesse caso, estamos nos referindo aos complexos autônomos da psique (inconscientes), que se constitui de sonhos, visões, alucinações patológicas e ideias delirantes.

Os complexos de tonalidade afetiva vêm colocar em questão o conceito ingênuo da unidade da consciência, que é identificada com a psique.

Os afetos fortes sempre escondem complexos. E toda constelação de complexos supõe um estado perturbador de consciência, afetando não só as intenções da vontade, da memória, do pensamento, como também algumas vezes pode distorcer a própria ação.

A liberdade vivida pelos complexos se deve à inconsciência que temos dos mesmos; estes, às vezes, chegam a assimilar o próprio complexo do eu ocasionando uma modificação inconsciente na personalidade. Todavia, os complexos autônomos podem aparecer como tudo o que ainda não é consciente não associado ao eu - como qualidades de pessoas estranhas, quero dizer, como projeções.

Os complexos pessoais, isto é, aqueles compostos pela história pessoal do indivíduo, e de conteúdos conflitivos reprimidos, guardam em seu núcleo a impessoalidade.

Ao despojar um complexo de sua capa pessoal, encontraremos o verdadeiro núcleo do complexo, o ponto nodal do inconsciente coletivo, não mais sufocado pelo excesso de material pessoal - não mais patológico - senão fecundo como uma célula doadora de energia. Fundamento de todos os seres, de toda espécie de existência, o fundo comum é um eterno acontecer, um mar de possibilidades virtuais.

As imagens definem a essência da psique e são a base afetiva dos complexos. Elas, além de possuírem 
uma coerência interna, estão dotadas de totalidade própria e gozam de um grau relativamente elevado de autonomia.

A iniciativa de Jung neste território imaginário possibilitou a visão de uma personalidade que já não tem um só centro, mas muitos. Uma vez que compreendemos que cada um de nós é normalmente um fluxo de figuras, já não nos sentimos ameaçados quando falamos com elas sem que isso signifique em absoluto a loucura. 0 próprio Jung, quando experimentou a personificação de várias figuras descritas em sua autobiografia, as levou a sério, tanto que desenhou seus traços, falou às vozes que lhe falavam e anotou o que lhe diziam. Experimentou-as imaginariamente possibilitando desse modo o acesso à compreensão.

As fantasias levaram Jung a compreender que existia algo nele capaz de pensar e dizer coisas independentemente de sua vontade. As estranhas fantasias dotadas de emotividade, dificilmente explicadas pela história de vida da pessoa, buscarão eco na história da humanidade, na cultura, nos mitos religiosos e nas fantasias coletivas (Jung, 1975).

Em qualquer momento, a constelação ou ativação de um arquétipo pode fazer surgir uma fantasia estranha, uma imagem dotada de emotividade, dificilmente justificada pela história pessoal do indivíduo.

\section{0 mundo da pós-modernidade e da pluralidade}

$$
\begin{array}{r}
\text { "Dar a cada emoção uma personalidade } \\
\text { A cada estado de alma } \\
\text { Uma alma" } \\
\text { Fernando Pessoa, Livro do Desassossego }
\end{array}
$$

É o artista, compreendido a partir do pensamento da escola da Ilustração e da escola Romântica, que nos permite chegar ao mundo da pós-modernidade e à ideia da pluralidade. Aqui, a explosão da multiplicidade contrapõe-se à visão do homem da Ilustração.

Como tendência geral do pensamento da Ilustração, as ideias de Razão e Natureza - ideias reguladoras do século XVII - desempenharam no século XVII a função de conceitos limitantes sobre o homem e o mundo.

0 grande tema da cultura Renascentista é a natureza e o caminho que conduz a esta é à razão. Em nome da razão, havia sido desenvolvido o melhor da cultura da época: a ciência, a ideia da liberdade, da tolerância, da dignidade humana, a ideia de progresso da humanidade, entre outras; assim como as ciências receberam uma nova orientação, a arte, por sua vez, também foi submetida à mesma exigência. Ela deveria ser contrastada pela razão, ser provada de acordo com as regras racionais; não existiria nenhum outro meio de comprovar se a arte possui um conteúdo autêntico. A exemplo da ordem que Newton havia estabelecido no universo físico, deveria derivar a ordem do universo intelectual, ético e estético.

Existe uma crise de identidade? Quem é este sujeito moderno? A questão sobre a identidade vem assumindo grandes proporções desde que as antigas identidades não satisfazem mais ao homem contemporâneo.

Stuart Hall (1998) responde não só que existe uma crise de identidade, mas também explora todo o tempo a afirmação de que as identidades modernas estão sendo descentradas, fragmentadas. Aquele sujeito com uma identidade unificada, ao redor do eu, estável, fixa já está assumindo mais uma multiplicidade de identidades, algumas umas vezes instáveis, outras contraditórias, buscando direções diferentes.

É na concepção de identidade da Ilustração que vamos encontrar um sujeito unitário, totalmente centrado no eu, individualista dotado das capacidades da razão, fundamentado no "cogito, ergo sum" de Descartes. Um homem "... centrado na imagem do Homem racional, científico, liberado do dogma e da intolerância, e diante do qual se estendia a totalidade da história humana, para ser compreendida e dominada" (Hall, 1998).

O descentramento do sujeito da Ilustração, visto como portador de uma identidade estável e fixa, dá lugar a um indivíduo cuja identidade se revela aberta, inacabada, fragmentada. 0 Romantismo é a primeira fissura desse sujeito unitário, indivisível, transparente para si mesmo, quer dizer, o sujeito consciente.

Essa nova concepção de sujeito retoma no Romantismo algumas características, por exemplo, a figura do duplo na literatura, que irá compor o sujeito da modernidade tardia (segunda metade do século XX).

Com a desconstrução do sujeito moderno no mundo da arte e no mundo intelectual, uma nova identidade está surgindo com o sujeito cuja psique é plural, múltipla. 


\section{0 duplo na literatura e o direito de existir dos vários personagens da alma}

"Vivem em nós inúmeros;

Se penso ou sinto, ignoro Quem é que pensa ou sente. Sou somente o lugar Onde se sente ou pensa

Tenho mais almas que uma. Há mais eus do que eu mesmo. Existo todavia" Fernando Pesssoa, Obra Poética, p. 291

Termo consagrado pelo Romantismo, Doppelgänger se traduz por duplo ou "segundo eu", de acordo com Jean-Paul Richter (1796); significa literalmente aquele que caminha ao lado, companheiro de caminho ou segundo o próprio Richter "as pessoas que veem a si mesmas".

Nessa reflexão, outorgamos prioridade ao caminho que nos leva à questão da identidade. 0 mito, as obras literárias, em particular a ficção fantástica onde o duplo está bem representado, e a visão psicanalítica.

Estamos diante de um tema ancestral que na literatura terá sua apoteose no movimento romântico. 0 mito do duplo remonta a épocas mais antigas, quando lendas nórdicas e germânicas já relatavam o encontro com o duplo.

O mito do duplo no Ocidente está em consonância com o conceito de subjetividade lançado no século XVII ao formular a relação sujeito-objeto; até então prevalecia a tendência à unidade. Desde a Antiguidade até o século XVI, o mito do duplo simbolizava o homogêneo, o idêntico. Já no século XVI o duplo começa a representar o heterogêneo, ou seja, com a divisão do eu chegamos à ruptura da unidade (século XIX), alcançando no século XX um fracionamento da identidade. Essa evolução é um reflexo da nova concepção que se tem do lugar ocupado pelo homem na natureza.

$\mathrm{O}$ século XX se mantém na questão do heterogêneo, com a psicanálise; assim o mito do duplo continua sendo atual como figura privilegiada do heterogêneo.

Dom Quixote aspira ser o duplo encarnado dos heróis dos romances de cavalaria, e ao duplicar-se, objetiva seu drama interior. Don Juan multiplica as identidades falsas para seduzir com a cumplicidade da noite. Em Fausto, a dissociação está longe de ser um enfraquecimento, pois é a divisão que vai instaurar uma relação viva, dialética com o mundo: o homem dilacerado, condição da liberdade do homem.

O sujeito dividido, tal como aparece na literatura sob a forma de duplo é testemunha da profunda mudança na concepção da identidade do homem pós-moderno. 0 eu soberano que se expressava no cogito dá lugar ao "Quem fala por mim?".

A psique dá provas em diversas estâncias, seja pelo estudo dos sonhos em A interpretação dos sonhos (Die Traumdentung, 1900), de Freud, seja pelo descobrimento do inconsciente de Jung, de que a multiplicidade faz parte da condição humana e que o acesso ao simbólico se conclui pela fragmentação da psique.

A influência do descobrimento do inconsciente sobre a literatura no começo do século XX é determinante. $\mathrm{O}$ duplo como vimos, é uma figura privilegiada dos dramas dos escritores que mergulham no território do inconsciente para confessar-se, desdobrando-se para reencontrar sua unidade original.

Com Pirandello, observamos que a confissão da consciência tem que ser dupla em $O s$ eu: diálogos do pequeno eu com o grande eu (1897-1906). Este sempre foi seu tema principal, tanto no teatro como na ficção: o drama do sujeito dividido, em que a única realidade do eu está em seu oposto, o inconsciente. 0 duplo é um leitmotiv em seus contos, romances e no teatro, sobretudo sob o tema do aprisionamento da personalidade, como Matia Pascal no romance Il fu Mattia Pascal (1904), obra em que o autor consegue levantar o véu do mistério que encobre a psique, descobrir o rosto coberto pela máscara e revelar a marionete manipulada pelos outros. E o duplo tem uma função capital nessa elucidação: ele é a metáfora do original.

A literatura tem a vocação de colocar em cena o duplo, proibindo o princípio da identidade, dando a muitas outras vidas o direito de ser e de existir.

A vontade e extinguir o eu, de escapar do eu ou fugir por meio da imaginação é uma constante na literatura contemporânea, principalmente na de ficção.

Em um mundo que vive uma crise de identidade, o sonho assim como a poesia nos permite uma aproximação com o mundo arquetípico, na qual a verdade e o erro não são critérios absolutos.

Com o poeta Fernando Pessoa, e seus heterônimos, não é diferente. É sim incomparável, pois não estamos falando de uma ou duas, mas de suas múltiplas vozes; ele realiza o acolhimento do duplo e em um processo mais profundo dialoga com o mundo interno. Seus personagens são reais, têm filiação, profissão, ou seja, eles existem. Com a pluralidade, 
o homem vive as ficções em vários níveis, abrindo possibilidades para que o homem confinado e com medo de perder sua essência, ultrapasse seus limites e se abra para mundos possíveis, e o duplo é uma figura privilegiada da ficção.

As ambiguidades, a incerteza, a indecisão fazem parte do refinado jogo de intercâmbio entre os personagens que procuram existir em busca de um autor que lhes proporcione um roteiro e uma história.

\section{Poemas em busca de poetas}

\author{
"Eu sinto a minha vida de repente \\ Presa por uma corda inconsciente \\ A qualquer mão noturna que me guia" \\ Fernando Pessoa, Obra Poética, p. 129
}

Três autores modernos de diferentes partes do mundo, um italiano, um suíço e um português, no início do século XX defendem um fundo comum: o inconsciente como multiplicidade. Pirandello (1867-1936), Fernando Pessoa (1888-1935) e Jung (1875-1961) - um dramaturgo, um poeta e um psicanalista - recebem respectivamente personagens, poemas e imagens do inconsciente, conseguem acolhê-las e trabalhar com as imagens primordiais que lhes chegam. Existe um fundo comum que está presente em vários autores, e eles recebem algo desse fundo, desse todo, que também pode ser múltiplo.

São os personagens, as imagens e os poemas que estão em busca de um autor que possa recebê-las. As imagens primordiais invadem e encantam o autor buscando ser acolhidas por ele. Com Pirandello, Pessoa e Jung é possível um paralelo, uma reflexão sobre a multiplicidade do inconsciente.

Pirandello, um dos paradigmas da ficção moderna mescla o verdadeiro e o falso e desveste a literatura italiana do século XX do provincianismo que lhe sufocava com duas obras revolucionárias que marcaram definitivamente a noção do sujeito pós-moderno: Um, nenhum e cem mil e Seis personagens em busca de um autor. Nessas obras, ao mesmo tempo em que o autor joga com o real e com a fantasia, nos revela o surgimento desse sujeito múltiplo.

Cada personagem ganha vida do autor e se apresenta com características e necessidades próprias, valor poético e significado na peça, sentem tudo, sofrem. Possuem forma e paixão. 0 nascimento é real ainda que o drama dos personagens não tenha um desenvolvimento lógico e ordenado, ao contrário, se mostra arbitrário, caótico, complicado, ou melhor, romântico.

A saída pirandelliana para esse sujeito superficial e egocêntrico é que cada um pode ser um, nenhum, cem mil, ainda que a vida force o homem à vivência trágica de ser um. 0 autor traz à tona a explosão da multiplicidade como resposta ao sujeito cartesiano da modernidade. Encontra a resposta não mais na objetividade do conhecimento, como anteriormente, senão na "coexistência dos opostos", onde não encontramos diferença entre o eu e o mundo e o intelecto cede lugar à poesia. A consciência cede lugar ao inconsciente.

0 poeta português Fernando Pessoa, com a pluralidade de vozes, nos remete ao fundo comum, ao inconsciente, fonte de inesgotável criação povoada por poemas em busca de um poeta.

A invenção dos heterônimos, pelos quais assume identidades diferentes, foi a resposta encontrada por Pessoa para a identidade cultural representada pelo sujeito unificado, em crise, em declínio. Originados no espaço da invenção, os heterônimos explodem de maneira profética anunciando a fragmentação do indivíduo moderno. Com Fernando Pessoa, não estamos falando de uma ou duas, mas de suas múltiplas vozes, as quais são acolhidas por ele e em um processo mais profundo dialogam com o mundo interno. Seus personagens são reais, têm filiação, profissão, ou seja, eles existem. Com a pluralidade, o homem vive as ficções em vários níveis, abrindo possibilidades para que o homem confinado e com medo de perder sua essência, ultrapasse os limites e se abra para mundos possíveis. As ambiguidades, a incerteza, a indecisão fazem parte do refinado jogo de intercâmbio entre os personagens que procuram existir em busca de um autor que lhes proporcione um roteiro e uma história.

Cada época tem sua concepção de sujeito, como de tudo; Pessoa esboça as linhas gerais de uma concepção de sujeito que se configurará, ao longo de nosso século, na filosofia, na psicanálise e na linguística.

Ao criar seus heterônimos culminou uma tendência que vinha manifestando-se na literatura europeia desde o Romantismo, e que desde a virada do século XX se multiplica na literatura ocidental que se dirigem do estético para a vanguarda.

Poetas e romancistas multiplicam a semi-heteronímia, atribuindo obras a personalidades cuja criação como tais resultam da própria obra que lhes é 
atribuída ou que o autor descreve. A direção heteronímica, de ser "outro" na pessoa de outro é típica de toda vanguarda em maior ou menor grau.

Ao nascer do fundo comum, Campos, Reis e Caeiro - classificados pelo poeta como "manifestações sinceras" - ganham vida própria e os diferentes "eus" são tratados como elementos autônomos, como partes de um todo desconhecido.

Pessoa, Pirandello e Jung foram mais longe e assinalaram a fragmentação ontológica do sujeito moderno. Foram mais longe porque não se limitaram a mostrar que somos muitos segundo o momento e o lugar; com coragem, acreditaram e registraram o desdobramento do sujeito unificado, portador de uma psique que é plural, múltipla.

O surgimento dos heterônimos na situação que Fernando Pessoa denominou Dia Triunfal se produziu na emergência das distintas figuras da personalidade múltipla do poeta. A força das imagens mostra uma alma multifacetada, sem a colaboração da consciência, onde a sua natureza mais íntima se revela e é o Self quem fala. É o predomínio do inconsciente sobre a consciência, que contempla o fenômeno como mera observadora. É a sua obra que se impõe com maior força que sua vontade.

A personalidade é imaginativamente percebida como um drama vivo e cheio de gente, do qual parte o eu, mas ele não é o único ator, nem diretor e nem sempre o personagem principal. No fenômeno criativo eu pode ser um obstáculo, um embusteiro, um ilusionista, sempre que tenta manipular valores, quando não se encontra diferenciado das fantasias do inconsciente coletivo.

0 poeta observa de longe, questiona sua unidade e se põe em processo. É um trabalho sem fim a tarefa das subpersonalidades em busca da unidade, da totalidade tema que se faz presente em toda a sua obra.

Fernando Pessoa fez sua opção e esta foi pelo mundo interno, apesar de toda dor da vivência do eu dilacerado. É o mito do homem fáustico vivido dramaticamente por aquele que valentemente se aventurou no reino da alma. Pessoa foi recebendo as imagens, os poemas do fundo comum e foi capaz de suportar a tensão dos opostos, e com sua poesia revelou a possibilidade de redesenhar o sujeito moderno, desconstruído em pontos fundamentais: apresentou um homem que pouco tem de comum com o homem cartesiano.

Quem sou? pergunta-se inúmeras vezes. Escreveu partindo de vários personagens em busca dessa resposta para encontrar a si mesmo. Os personagens em busca de existência, de pensamentos, de poemas, marcam o processo do poeta. 0 desejo de saber-se quem é não é entendido aqui como falta, como um desejo que nunca se realiza, mas como uma busca pela totalidade. É o inconsciente que transborda e oferece para o indivíduo, sujeito de sua própria obra, novos e mais altos valores.

Na concepção junguiana, o inconsciente coletivo enquanto fonte de criatividade é concebido como excesso: é o eterno devenir, um mar de possibilidades que contém os opostos. 0 acesso a esse mar de criatividade fez com que Pessoa se desdobrasse nos sujeitos heteronímicos.

Jung, Pirandello e Pessoa concebem a psique como pluralidade e desmontam a ideia de sujeito unitário, fundado no eu, tão predicado pela Ilustração. A partir dessa percepção se rompe o conceito de unidade da psique e da preponderância da vontade. Nossa razão e nossa vontade se colocam subordinadas e impotentes diante do fundo comum, quer dizer, "somos subjugados por um mundo que foi criado por nossa psique" (Jung, 1984, VIII, p. 747).

As imagens primordiais vindas do fundo comum buscam uma oportunidade para transpor o intervalo entre inconsciente e consciente; porém, para isso, é necessário que sejam acolhidas por alguém: cabe ao artista recebê-las, diz Jung, um homem conectado com seu fundo comum, com seu mundo imagético. 0 artista é concebido como um homem privilegiado, no acesso ao mundo inconsciente, pois, diferente do homem comum, circula no campo intermediário entre o mundo consciente-inconsciente, como um pescador afortunado.

De acordo com Jung, as imagens da fantasia são acontecimentos fundamentais da existência, porque elas estão muito distantes da consciência e mais próximas do inconsciente. E toda consciência depende dessas imagens: "tudo mais - ideias da mente, sensações do corpo, percepções do mundo que nos rodeia, crenças, sentimentos - apresentam-se em forma de imagens para poder ser experimentados" (Hillman, 1999).

Para Jung, a imagem é a verdadeira realidade psíquica. Elas são o estatuto do indivíduo e da realidade, contrapondo toda a tradição do ocidente que predominantemente vê a imagem como uma reprodução da realidade. Ao outorgar valor à pluralidade da psique, à imaginação, à fantasia, Jung não está dando prioridade ao eu como depositário da construção da psique. 
Três autores modernos, um italiano, um português e um suíço, conseguem sincronicamente, desde diferentes lugares do mundo, escrever sobre o mesmo tema e apreender o mundo como múltiplo, o mundo da psique. A existência de um fundo comum, o inconsciente, de onde emanam possibilidades novas e criativas: os personagens, os poemas, as imagens.

Não existe qualquer conexão causal entre esses acontecimentos. Jung diz que tais coincidências se apoiam em organizadores que engendram por um lado imagens psíquicas e, por outro lado, o fato em si. São eventos que ocorrem simultaneamente, ou seja, no mesmo marco temporal, dentro de horas ou dias; porém não necessariamente no mesmo momento. Existe a coincidência no tempo dos acontecimentos, um psíquico e outro físico (pensamentos, poemas, imagens).

Para Jung (1984), o inconsciente suplanta a consciência no tocante à amplitude do saber possível; melhor dizendo, no inconsciente, conhecemos muitas coisas que não sabemos que sabemos. Podemos chamá-los de pensamentos não pensados ou conhecimentos apriorísticos inconscientes. Esse foi um grande salto intuitivo de Jung: que o inconsciente possui um conhecimento a priori, ou uma relação imediata de eventos que não tem qualquer base causal.

Essa noção leva Jung aos limites extremos de sua hipótese sobre a unidade da psique: se sabemos coisas que estão mais além de nossa possibilidade consciente de conhecimento é porque existe em nós um conhecimento desconhecido, um aspecto da psique que transcende as categorias de tempo e espaço e está presente aqui e ali, lá de tempos em tempos. Esta é a realidade psíquica denominada por Jung de Self.

Da mesma forma como pode ser aplicado à história do indivíduo, pode ser aplicado à história coletiva. Como base para uma nova visão de mundo, a sincronicidade requer uma forma de pensar inteiramente nova sobre a natureza e a história.

Encontrar um significado nos eventos históricos pressupõe que o inconsciente organiza a história com a finalidade de produzir algum avanço da consciência, um avanço para o entendimento da realidade seja ela terrível e sombria ou gloriosa e luminosa. Dessa forma, cada um de nós é portador de um fragmento da consciência que os tempos necessitam para ampliar o conhecimento dos motivos subjacentes que se desdobram na história.

0 inconsciente do artista estaria a serviço dos tempos, compensando a unilateralidade da cultura, não só da consciência do próprio indivíduo, como também do coletivo. Assim, o artista e o homem comum são cocriadores do reflexo da realidade que a história como um todo revela.

\section{Conclusão}

\author{
"Multipliquei-me para me sentir, \\ Para me sentir, precisei sentir tudo \\ Transbordei, não fiz senão extravasar-me, \\ Despi-me, entreguei-me, \\ E há em cada canto da minha alma um altar a um deus \\ diferente" \\ Fernando Pessoa, Obra Poética, p. 345
}

Jung privilegia as imagens e a psique como plural e não atribui ao eu a prioridade, como o autor principal da construção da psique. É o inconsciente quem predomina no ato criativo. A consciência do autor fica afastada e observa o fenômeno enquanto é invadida por ideias e imagens que jamais pensou escrever.

Fernando Pessoa nos diz com sua poesia que é possível conviver com vários, viver a divisibilidade da psique sem isso seja loucura ou enfermidade psíquica. Nenhum dos poetas heterônimos foi chamado ao palco psíquico, eles surgiram. E Pessoa os acolheu e dialogou com eles. Quando o processo de individuação se inicia, sinônimo de um inconsciente que se manifesta de forma avassaladora, toda a sua autonomia é revelada.

0 eu do poeta, com o efeito avassalador das fantasias-poemas do Dia Triunfal, encontrou-se entre duas atitudes psíquicas: adaptar-se à realidade e acolher os novos conteúdos inconscientes. Essa dupla atitude cessa à medida que a intensidade do processo diminui; porém, quando a atividade das fantasias é intensa, como no caso de Pessoa, o eu se dissocia até certo ponto na tentativa de acolher e elaborar as novidades psíquicas que chegam sem cessar.

Buscar a unidade no conjunto da obra foi a forma particular, subjetiva que o poeta "escolheu" para cuidar de seu processo. Para Jung, toda construção e reflexão teórica estão dirigidas para a concepção moderna do sujeito unitário centrado no eu e portador de uma identidade fixa e contínua. A resposta para esse homem é o sujeito divisível, fragmentado, plural.

As figuras da imaginação, quando despotencializadas pelo diálogo, enriquecem continuamente a personalidade. Essas figuras, enquanto permanecem nesse 
diálogo, não estarão atuando como possessões, como complexos autônomos. E a comunidade psíquica, com todos seus personagens, vai manter-se múltipla.

Existem partes da psique que devem ser trabalhadas, educadas e diferenciadas, fruto de um trabalho psicológico intenso. Esse trabalho de diferenciação, ao contrário de criar ilhas isoladas de rigidez, vai despotencializando o eu, pois quando se diferencia, está em realidade conquistando o inconsciente coletivo. 0 eixo central em que se produz a transformação é a diferenciação entre o eu e o si mesmo. A ideia de uma integração definitiva do indivíduo, que negue às figuras o direito a manifestação, não está presente no esquema junguiano.

A individuação tem uma meta e inclusive ainda que ela não seja alcançada, o diálogo permanece na esfera psíquica, não se unifica. É a estrutura subjetiva e não a egoica quem vai atuar no processo decisório, uma multiplicidade de representações psíquicas que são consultadas para decidir e atuar; nada funciona separadamente.

0 eu ocupa uma função ativa e importante: o eu precisa do Self e vice-versa. 0 eu e o Self são duas grandezas cujo diálogo constrói o campo da experiência. No entanto, no momento da decisão, não é ele e nenhuma parte isolada da psique que vai decidir, mas sim um símbolo.

E para alcançar a vivência simbólica, algo da parte instintiva terá que morrer, quer dizer, por meio do trabalho psicológico. No símbolo, os opostos estão presentes sem que possam ser identificados, pois desaparecem como tais. Com isso se produz uma novidade, uma nova síntese e apreendemos o nascimento de uma nova forma de estar no mundo.

Não existe diferenciação sem participação e cooperação da personalidade consciente, e grande parte do sofrimento que vem desse processo é porque a personalidade consciente se rebela contra a ideia de responsabilizar-se por algo que não escolheu.

No momento em que a personalidade se diferencia cabe a ela uma responsabilidade a mais: decifrar o enigma presente nos símbolos e sua realização social, e ao decifrar os símbolos, não temos garantias, só responsabilidades.

Jung (1984) diz inclusive que aquele que adquire certa compreensão das imagens do inconsciente, acreditando que é suficiente fixar-se em tal saber, torna-se vítima de um erro perigoso. Isso porque quem não sente a responsabilidade ética que seus conhecimentos comportam, sucumbirá ao princípio de poder. Disso poderão resultar efeitos destrutivos não só para os outros como também para a própria pessoa. As imagens do inconsciente impõem ao homem uma pesada obrigação. Sua compreensão assim como a falta de sentido da responsabilidade ética priva a existência de sua totalidade e confere a muitas vidas individuais uma marca de pessoa fragmentada (Jung, 1984).

Individuar-se exige tornar-se consciente da Weltanschauung moderna, ou seja, de tudo o que é avaliado unilateralmente não só como verdadeiro e bom, como também os aspectos feios, malvados e sombrios.

Ao longo desse processo de desenvolvimento e diferenciação, o homem, impulsionado por forças instintivas inconscientes, tem um caráter peculiar: é capaz de tomar consciência desse desenvolvimento e influenciá-lo.

Ao reconhecer os aspectos sombrios, diferenciar os complexos, diminuir as projeções, assimilar aspectos parciais da psique e descer ao fundo comum dos abismos, e realizar o confronto entre consciente e inconsciente, o homem produz um alargamento do seu mundo interior. $\mathrm{O}$ indivíduo já não está fragmentado interiormente. Não se reduzirá a um pequeno eu rígido dentro de estreitos limites. Esse novo homem agora abraça valores mais amplos absorvidos do imenso patrimônio que a espécie acumulou em suas estruturas fundamentais.

Jung, ao convocar esse homem a enfrentar suas partes feias e sombrias e reconhecê-las no seu limite, o convida também a responsabilizar-se por elas, pois a cada crescimento do homem também seu lado oposto tem de crescer.

Personificar as fantasias é diferenciá-las do inconsciente coletivo, é dedicar-se a elas, tentar compreendê-las, é dotá-las de memória. Essa é a maneira particular que Fernando Pessoa encontrou para dar voz a seus poemas.

Quando Fernando Pessoa se pergunta "Quem sou?", está nos convidando de alguma maneira a perguntarmos "Quem somos?". E mais, está nos provocando com sua poesia a cuidarmos das múltiplas partes de nossa alma.

\section{Referências}

Cassirer, E. (1992) Filosofia do iluminismo (crítica e interpretação). São Paulo: Ed. Unicamp. 
Hall, S. (1998). A identidade cultural na pós-modernidade. São Paulo: DP.

Hillman, J. (1992). Re-visioning psychology. New York: Ed. Harper-Perennial.

Jung, C. G. (1975). Memórias, sonhos, reflexões. (D. F. da Silva, Trad.). Rio de Janeiro: Ed. Nova Fronteira.

Jung, C. G. (1984). Dinâmica do inconsciente. In C. Jung. Obras Completas. (L. Bonaventure, L. Boff, D. M. R. F. da Silva \& J. Bonaventure, Trad.). Petrópolis: Vozes.

Nerval, G. (1991). Aurélia. São Paulo: Ed. Iluminuras.
Pessoa, F. (1965). Obra poética. (M. A. Galhoz, Org.). Rio de Janeiro: Ed. Aguilar.

Pessoa, F. (1966). Páginas íntimas de auto-interpretação. Lisboa. Ed Ática.

Pirandello, L. (1981). Seis personagens em busca de um autor. (B. Pedreira, Trad.). São Paulo: Ed.Victor Civita.

Pirandello, L. (2000). Um nenhum e cem mil. (M. S. Dias, Trad.). São Paulo: Ed. Cosac Naify.

Richter, J. P., \& Rank, O. (1796). El doble (F. Mazía, Trad.). Buenos Aires: Orion. 